\title{
A PROSPECTIVE CLINICALTRIAL OF AMLODIPINE IN COMPARISON TO PERINDOPRIL
}

\author{
SUPRAVA DAS ${ }^{a}$, MYAT THU THUWINa, SHERLY DEBORAH G. a , LUBNASHIRIN ${ }^{b}$, MOHAMMAD SHAHJAHAN \\ KABIR $^{\mathrm{b}}$,SRIDEVI CHIGURUPATI ${ }^{*}$
}

a,cFaculty of Medicine, AIMST University, Semeling, Bedong, Kedah, Malaysia, bFaculty of Medicine, QUEST International University Perak, Ipoh, Perak, Malaysia, cFaculty of Pharmacy, AIMST University, Semeling, bedong, Kedah, Malaysia.

Email: sridevi.phd@gmail.com

Received: 27 Aug 2017 Revised and Accepted: 02 Nov 2017

ABSTRACT

Objective: The objective of this research was to perform a prospective clinical trial to compare antihypertensive effects of amlodipine and perindopril in hypertensive patients.

Methods: In our study, we compared antihypertensive effects of well tolerated and commonly used antihypertensive drugs, amlodipine and perindopril. There were 81 hypertensive patients of both sexes over $40 \mathrm{y}$ of age without other diseases included in this prospective clinical trial. Forty (40) patients were treated with amlodipine ( $5 \mathrm{mg} /$ day) and forty-one (41) patients were treated with perindopril (4 mg/day). After one month of taking both drugs, blood pressure was measured in the supine position with a standard mercury sphygmomanometer in the morning.

Results: Amlodipine and perindopril groups were having almost similar characteristics at the beginning of the study. There was significantly decrease insystolic blood pressure (sBP) throughout the study period in the amlodipine group ( $\mathrm{p} \leq 0.05$ ) but not in the perindopril group. The efficacy of amlodipine over perindopril on systolic blood pressure and diastolic blood pressure (dBP) was significant ( $\mathrm{p} \leq 0.001$ for $\mathrm{sBP}$ and $\mathrm{p} \leq 0.05$ for $\mathrm{dBP}$ ).

Conclusion: It may be concluded that the antihypertensive efficacy of amlodipine was superior when compared to perindopril.

Keywords: Amlodipine, Perindopril, Comparative efficacy, Hypertension

(C) 2017 The Authors. Published by Innovare Academic Sciences Pvt Ltd. This is an open access article under the CC BY license (http://creativecommons.org/licenses/by/4.0/) DOI: http://dx.doi.org/10.22159/ijpps.2017v9i12.22270

\section{INTRODUCTION}

Clinically, hypertension is defined as that level of blood pressure (BP) at which the institution of therapy reduces blood pressure related morbidity and mortality [1]. According to British Hypertension Society (BHS) blood pressure is categorized by $\mathrm{BP}<120 / 80 \mathrm{mmHg}$ is optimal, $<130 / 85 \mathrm{mmHg}$ is normal, 130 $139 / 85-89 \mathrm{mmHg}$ is high normal, grade-1 hypertension (mild) is 140-159/90-99 mmHg, grade-2 (moderate) is $160-179 / 100-109$ $\mathrm{mmHg}$, grade- 3 (severe) is systolic $\geq 180$ and diastolic $>110 \mathrm{mmHg}$ [2]. Antihypertensive drugs are being used tremendously since long time ago. In Bangladesh, the prevalence of hypertension was 14.4\% with systolic blood pressure (sBP) $\geq 140 \mathrm{mmHg}$ and $9.1 \%$ with diastolic blood pressure $(\mathrm{dBP}) \geq 90 \mathrm{mmHg}$. Studies from India and Bangladesh have shown an upward trend in the prevalence of hypertension [3]. For developing countries it is one of the most vital problems and if leave untreated leading serious and life threatening conditions [4] of the body like heart disease, stroke, end-stage renal failure, and peripheral vascular disease. Antihypertensive treatment can decrease the rate of cardiovascular morbidity and mortality [5] also alleviates the progression of chronic kidney disease [6]

In United States, 77\% of adults with hypertension used at least one antihypertensive medication in large scale of survey [7]. During last $20 \mathrm{y}$; several major therapeutic advances have markedly improved the prognosis of patients with coronary artery disease (CAD) [3]. There are 5 classes of drugs used for the treatment of hypertension and prevention of cardiovascular morbidity [5]. Among these drugs, two of them; angiotensin converting enzyme (ACE) inhibitors and calcium channel blockers (CCB) were used in this study to demonstrate their beneficial effects in hypertensive patients [8]. Antihypertensive drugs amlodipine and perindopril are widely used due to the low incidence of adverse drug reaction and they are well tolerated. ACE inhibitors decrease the production of angiotensin II, increase bradykinin levels and reduce sympathetic nervous system activity [1]. Blockage of bradykinin breakdown and enhancement of prostaglandin release may probably participate in the antihypertensive activity of ACE-inhibitors [9]. Perindopril is long acting member of ACE inhibitors. This is a prodrug and is converted to the active agent by hydrolysis, primarily in the liver [1]

Calcium channel blockers block voltage-gated calcium channels in the heart and vasculature [10]. They reduce vascular resistance, which reduces intracellular calcium and blunts vasoconstriction [1] due to long lasting relaxation of smooth muscle and a reduction in contractility throughout the heart. On heart, it also decreases SA node rate and AV nodal conduction velocity [11]. Only about one third of all hypertensive patients receiving therapy, however, have reached their goal blood pressure $(<120 / 80 \mathrm{mmHg})$. By controlling $\mathrm{BP}$ can reduce the risk of developing myocardial infarction, heart failure, stroke and renal disease in hypertensive patients [12]

\section{MATERIALS AND METHODS}

A double-blinded, randomized, parallel-group study was conducted in the Department of Pharmacology, Sylhet MAG Osmani Medical College, Bangladeshfor $30 \mathrm{~d}$. Eighty-one (81) diagnosed hypertensive patients of both sexes of aged between 40 to 80 y were taken from the Department of Medicine of Sylhet MAG Osmani Medical College Hospital, Bangladesh.

Permission of research was taken from ethical committee of Sylhet Osmani Medical College. Written informed consent was obtained from each patient before starting the trial. Among 81 patients 52 were male $(64.2 \%)$ and 29 were female (35.8\%). The patients were randomly allocated to treatment with either amlodipine $5 \mathrm{mg}$ once a day $(\mathrm{n}=40)$ or perindopril $4 \mathrm{mg}$ once a day $(\mathrm{n}=41)$, for $30 \mathrm{~d}$. Hypertensive patients with other co-morbidities like diabetes mellitus (DM), chronic obstructive pulmonary disease (COPD), and renal failure (RF) were excluded from the study. Then, data were collected by using a pre-diagnosed questionnaire. Blood pressure was measured with a standard mercury sphygmomanometer in the supine position in the morning and safety assessments were made throughout the study period.

\section{Statistical analysis}

All the data were presented as mean \pm standard deviation (SD) at $95 \%$ confidence interval $\left(\mathrm{CI}_{0.95}\right)$. Statistical analysis was done by applying unpaired t-test using Graph pad prism software version 5.0. 


\section{RESULTS}

Baseline characteristics were almost similar in both study drug groups shown in table 1 . In amlodipine study group, total subjects were 40 (male and female ratio was 22/18) whereas, in perindopril study group total subjects were 41 (male/female ratio was 30/11). At the beginning of the study lying sBP in both amlodipine and perindopril groups were $146.13 \pm 12.88 \mathrm{mmHg}$ and $149.27 \pm 12.97 \mathrm{mmHg}$ respectively and lying $\mathrm{dBP}$ were $90.50 \pm 6.28 \mathrm{mmHg}$ and $89.76 \pm 5.36$ $\mathrm{mmHg}$ respectively. The $\mathrm{sBP}$ and dBPchanges within same study groups are depicted in (fig. 1). There was significant decrease of sBP in amlodipine treated group after $30 \mathrm{~d}$, but no significant reduction of $\mathrm{dBP}$. The sBP and $\mathrm{dBP}$ in perindopril treated group were not reduced and tentative to increase (fig. 2). The comparative antihypertensive efficacy of amlodipine and perindopril (fig. 3). There were significant differences of both sBP (amlodipine 141.58 $\pm 12.52 \mathrm{mmHg}$, perindopril $152.93 \pm 16.92 \mathrm{mmHg}$ ) ( $\leq 5001$ ) and dBP (amlodipine 89.38 \pm 7.44 $\mathrm{mmHg}$, perindopril $92.76 \pm 7.96 \mathrm{mmHg})(\mathrm{p} \leq 0.05)$ after $30 \mathrm{~d}$. There was obviously seen that amlodipine decreasedsBP more effectively ( $\mathrm{p} \leq$ 0.001) than $\mathrm{dBP}$.

Table 1: Demographic characteristics of the two studied groups

\begin{tabular}{lll}
\hline Study parameters & ${\text { Amlodipine mean } \pm \text {SD }^{\mathbf{a}}}$ & ${\text { Perindopril mean } \pm \text { SD }^{\mathbf{a}}}$ \\
\hline Age (Years) & $54.10 \pm 9.49$ & $55.56 \pm 10.09$ \\
Weight (Kg) & $64.03 \pm 6.39$ & $68.32 \pm 4.77$ \\
Lying systolic BP (mm Hg) & $146.13 \pm 12.88$ & $149.27 \pm 12.97$ \\
Lying Diastolic BP (mm Hg) & $90.50 \pm 6.28$ & $89.76 \pm 5.36$ \\
\hline
\end{tabular}

The number of subjects selected for study $\mathrm{n}=81$ (amlodipine $\mathrm{N}=40$, perindopril $\mathrm{N}=41$ ). $\mathrm{a}=$ mean \pm Standard deviation (SD)

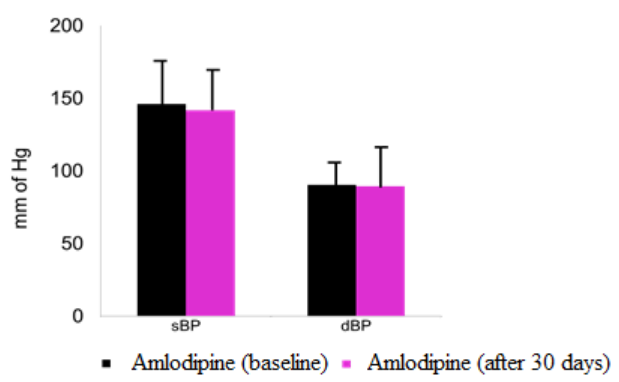

Fig. 1: Comparison of systolic blood pressure (sBP) and diastolic blood pressure (dBP) changes in mean \pm standard deviation in amlodipine studied group $(\mathrm{N}=40)$ at baseline and after $30 \mathrm{~d}$ of treatment

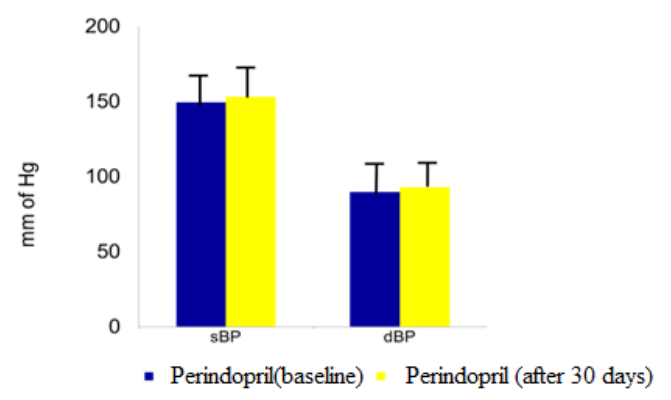

Fig. 2: Comparison of systolic blood pressure (sBP) and diastolic blood pressure (dBP) changes in mean \pm standard deviation in perindopril studied group $(\mathrm{N}=41)$ at baseline and after $30 \mathrm{~d}$ of treatment

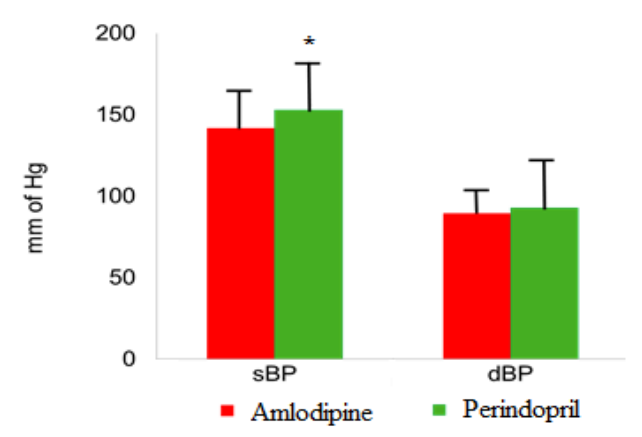

Fig. 3: Comparison of systolic blood pressure (sBP) and diastolic blood pressure (dBP) changes in mean \pm standard deviationbetween amlodipine and perindopril studied group $(n=81)$ after $30 \mathrm{~d}$ of treatment

\section{DISCUSSION}

Hypertension is an important worldwide public health challenge [13] which is associated with an increased risk of cardiovascular mortality, stroke and renal disease. So, controlling of blood pressure is essential for the prevention of high BP related morbidity on a long-term basis [14-16]. Although lifestyle modification can improve for managing hypertension, antihypertensive drug therapy is still needed for most hypertensive patients to control BP within normal limit [7]. There are many drugs for initial treatment of essential hypertension. Considering side effects, drug interactions and comorbid conditions, drugs like thiazide diuretics, ACE inhibitors, Angiotensin Receptor Blockers (ARBs), CCBs and $\beta$-blockers are used as first line drugs for the treatment of hypertension. Trials compared thiazide diuretics, ACE inhibitors, ARBs and CCBs-did not show consistent differences in outcome, efficacy, side effects or quality of life. $\beta$-blockers which are previously used as a first line therapy, have a weaker evidence base. Combination drug therapy hasmore advantageous than single drug therapy because of lesser side effects. In a study, it was evidenced that perindopril protected cardiovascular (CV) events of hypertensive patients in combination with other antihypertensive drugs. When perindopril was combined with either amlodipine or indapamide, maximal reduction of $\mathrm{BP}$ resulted indecreased CV deleterious effects [16]. CCB and ACE inhibitors might be the suitable combination in treating hypertension when ACE inhibitors monotherapy is not sufficient to control BP [17]. Though, initially single drug with lower initial doses are better tolerated, cost effective and have better compliance.

In our study, two commonly used drugs were compared on 81 hypertensive patients. Amlodipine was given to 40 patients, 5 $\mathrm{mg} /$ day and perindopril to 41 patients, $4 \mathrm{mg} /$ day. Amlodipine reduced both $\mathrm{SBP}$ and $\mathrm{dBP}$ from baseline. Amlodipine in compare with perindopril significantly reduced $\mathrm{sBP}(\mathrm{p} \leq 0.001)$ after one month but both drugs were well tolerated. Most frequent adverse effect of amlodipine was leg oedema (10.2\%) and perindopril was coughing $(12.5 \%)$. The result was comparable with some similar studies [18-19]. Zannad, Bernaud and Fay (1999) assessed the efficacy of amlodipine and perindopril [18] by Trough: Peak ratio from $24 \mathrm{~h}$ ambulatory BP recordings, before and after active treatment period $(60 \mathrm{~d})$. Both treatment groups produced comparable reduction in clinical sBP and $\mathrm{dBP}$ between ' 0 ' and ' 60 ' days. Both sBP and dBP were lowered in amlodipine treated patients than perindopril $48 \mathrm{~h}$ after last dose. Most frequent adverse effect was leg oedema in amlodipine $(19.1 \%)$ and coughing in perindopril (14.3\%). After omitting one dose, a condition imitating noncompliance, BP was more effectively controlled by amlodipine than perindopril.

Eguchi et al., (2004) compared Valsartan (an ARB) and amlodipine (CCB). In that study both drugs significantly reduced $\mathrm{sBP}$ and $\mathrm{dBP}$ $(p<0.002)$ [19]. Antihypertensive effect of amlodipine was superior 
to valsartan. Morning sBP was significantly reduced by amlodipine from 156 to $142 \mathrm{mmHg}(\mathrm{p}<0.001)$ but not by valsartan. Both agent reduced lowest night sBP to a similar extent (amlodipine 121 to 112 $\mathrm{mmHg}, \mathrm{p}<0.001$; valsartan 123 to $114 \mathrm{mmHg}, \mathrm{p}<0.002$ ). Reduction of morning sBP surge (morning sBP minus lowest night sBP) was significantly greater in patients treated with amlodipine compared those treated with valsartan $(-6.1 \mathrm{mmHg} v \mathrm{vs}+4.5 \mathrm{mmHg}$. $\mathrm{p}<0.02)$. Amlodipine monotherapy was more effective than valsartan monotherapy in controlling $24 \mathrm{~h}$ ambulatory BP and morning BP in hypertensive patients.

\section{CONCLUSION}

In conclusion, our study showed that amlodipine has better efficacy than perindopril as initial monotherapy. It was suggested that amlodipine is the drug of choice in controlling BP in mild to moderate hypertension when compared with perindopril. Further studies are required comparing other antihypertensive drugs and with incresed sample size to identify the risks and benefits of amlodipine to prove its efficacy compared to other antihypertensive drugs as monotherapy in mild to moderate hypertension.

\section{Study limitation}

In our study the number of patients was limited (81) and the study duration was only one month.

\section{ACKNOWLEDGEMENT}

Authors are thankful to Sylhet MAG Osmani Medical College, Bangladesh, for providing the facilities to conduct the study.

\section{CONTRIBUTION OF AUTHORS}

I declare that this work was done by the authors named in this article and all liabilities pertaining to claims relating to the content of this article will be borne by the authors. Dr. Suprava Das and Dr. Myat Thu Thu Win and Dr. Sherly Deborah G collected and analysed the data, Dr. Lubna Shirin and Dr. Mohammad Shahjahan Kabir designed the studyand Dr. Sridevi Chigurupati helped in writing the manuscript and statistical calculations.

\section{CONFLICTS OF INTERESTS}

Declared none

\section{REFERENCES}

1. Kotchen, Theodore A. Hypertensive vascular disease. In: LongoDan L, Fauci Anthony S, Kasper Dennis L, Hauser Stephen L, Jameson J Larry, Loscalzo Joseph. editors. Harrison's Principles of Internal Medicine. $18^{\text {th }}$ ed. New York: McGrawHill; 2012. p. 2042-59.

2. Walker Brian R, Colledge Nicki R, Ralston Stuart H, Penman Ian D. editors. Davidson's Principles and Practice of Medicine. 22 $2^{\text {nd }}$ Edition. NewYork: Elsevier Health Sciences; 2014. p. 607-13.

3. Sayeed MA, Banu A, Haq JA, Khanam PA, Mahtab H, Azad KA. Prevalence of hypertension in Bangladesh: effect of socioeconomic risk factor on difference between rural and urban community. Bangladesh Med Res Counc Bull 2002;28:7-18.

4. Missiriya S, John J. Assess the prevalence of hypertension and knowledge regarding the prevention of stroke. Asian J Pharm Clin Res 2017;10:177-80.
5. Gu Q, Burt VL, Dillon CF, Yoon S. Trends in antihypertensive medication use and blood pressure control among United States adults with hypertension. Circulation 2012;126:2105-14.

6. Huang R, Feng Y, Wang Y, Qin X, Melgiri ND, Sun Y, et al. Comparative efficacy and safety of antihypertensive agents for adult diabetic patients with microalbuminuric kidney disease: a network meta-analysis. PloS One 2017;12:e0168582.

7. Moura CS, Daskalopoulou SS, Levesque LE, Bernatsky S, Abrahamowicz M, Tsadok MA, et al. Comparison of the effect of thiazide diuretics and other antihypertensive drugs on central blood pressure: cross-sectional analysis among nondiabetic patients. J Clin Hypertens (Greenwich) 2015;17:848-54.

8. Bertrand ME. Perindopril/amlodipine combination: an optimal synergy for cardiovascular protection. Eur Heart J Suppl 2009;11 Suppl:22-5.

9. Guazzi MD, Campodonico J, Celeste F, Guazzi M, Santambrogio G, Rossi Metal. Antihypertensive efficacy of angiotensin converting enzyme inhibition and aspirin counteraction. Clin Pharmacol Ther 1998;63:79-86.

10. Bhardwaj S, Balgir PP, Goel RK. Pharmacogenomics and personalized management of hypertension. J Crit Rev 2015;2:1-6.

11. Furn Daniel E, Ulrich Robert W. Nonsteroidal antiinflammatory, disease-modifying antirheumatic drugs, nonopioid analgesics and drugs used in gout. In: Katzung Bartram G. editor. Basic and Clinical Pharmacology. 10 $10^{\text {th }}$ ed. New York: McGraw-Hill; 2007. p. 621-25.

12. Horn JR, Hansten PD. NSAIDs and antihypertensive agents. Pharm Times 2016;72:111.

13. Rutuparna P, Merin D, Abraham S, Thomas NM, Hameed J. Assessment of clinical effectiveness of losartan and amlodipine in hypertensive patients with left ventricular hypertrophy. Asian J Pharm Clin Res 2017;10:368-71.

14. Jose A, Wilson D, George M, Thomas RK, Justin A. Comparative study on the beneficial effects of telmisartan and other antihypertensive agents in stroke patients. Int J Pharm Pharm Sci 2014;9:99-102.

15. Bronsert MR, Henderson WG, Valuck R, Hosokawa P, Hammermeister K. Comparative effectiveness of antihypertensive therapeutic classes and treatment strategies in the initiation of therapy in primary care patients: a distributed ambulatory research in therapeutics network (DARTNet) study. J Am Board Fam Med 2013;26:529-38.

16. Wang JG, Pimenta E, Chwallek F. Comparative review of the blood pressure-lowering and cardiovascular benefits of telmisartan and perindopril. Vasc Health Risk Manag 2014;10:189-200.

17. Wu HY, Huang JW, Lin HJ, Liao WC, Peng YS, Hung KY, et al. Comparative effectiveness of renin-angiotensin system blockers and other antihypertensive drugs in patients with diabetes: systematic review and bayesian network metaanalysis. Br Med J 2013;347:f6008.

18. Zannad F, Bernaud CM, Fay R. Double-blind, randomized, multicentre comparison of the effects of amlodipine and perindopril on $24 \mathrm{~h}$ therapeutic coverage and beyond in patients with mild to moderate hypertension. J Hypertens 1999;17:137-46.

19. Eguchi K, Kario K, Hoshide Y, Hoshide S, Ishikawa J, Morinari M, et al. Comparison of valsartan and amlodipine on ambulatory and morning blood pressure in hypertensive patients. Am J Hypertens 2004;17:112-7. 